\title{
University of Waikato, New Zealand
}

\section{Mark Houlahan}

\section{Review of Wild dialectics by Lisa Samuels}

\author{
Abstract: \\ Review of Lisa Samuels' poetry collection, Wild dialectics, 2012.
}

Biographical note:

Mark Houlahan is Programme Convenor and Senior Lecturer in English at the University of Waikato, Hamilton, New Zealand. He is President of the Australia and New Zealand Shakespeare Association and sits on the editorial Boards of the Global Shakespeare Series (Palgrave) and of The Journal of New Zealand Literature. He has co-edited Twelfth Night (with David Carnegie) for the Internet Shakespeare (http://ise.uvic.ca); a printed version of this will appear in the Broadview Shakespeare series later this year. He is currently co-editing books on Shakespeare and emotion (with RS White and Katrina O'Loughlin) and an essay assemblage, SteamPunks and Times Transshifters (with Kirstine Moffat).

Keywords:

Creative writing - Poetry - New Zealand - Lisa Samuels 


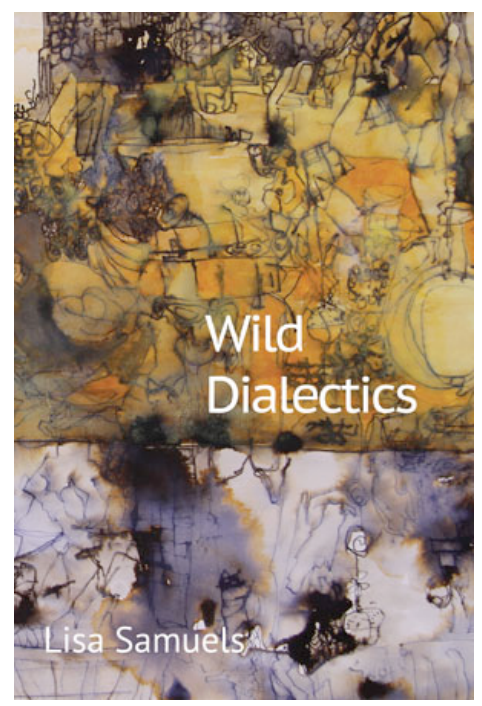

Wild dialectics

Lisa Samuels

Shearsman Books (UK), 2012

ISBN 978-1-84861-257-0

AU\$19.80

If the title Wild dialectics doesn't alert you to the kind of free flowing exuberance you can expect here, Samuels usefully prefaces these poems with two epigrams, one from Édouard Glissant: 'piling-up is the most suitable technique for exposing a reality that it is itself being scattered'; and the other from Stacy Doris, beginning: 'Logic can't explain water, though wet elucidates thought'. So here you should expect lines that pile up in order to evoke a dispersed grasp on the world; lines that accumulate according to water logic, not rock logic. In a sense these are formal poems, but they could not be unlocked with sustained exercises in new critical close reading. The volume begins and ends, as a physical unit, but the acts of perception it evokes travel out and beyond. Likewise specific poems begin and end, playfully evoking various forms, syllabic form, prose poem, even poems that take the shape of traditional poems, without needing to rhyme. But they do not reach for closure. They embrace openness.

Samuels is a New Zealand based American poet, teaching creative writing at Auckland University, but she eschews the specific anguishing of place, self and nation. Some version of her past is re-enacted, for example in the opening of 'The "land of freedom"': 'I studied in the wastes of Carolina that year'. This trails with it too the ghosts of Whitman and other confessional American poets, but the voice quickly moves with a splintering of syntax and specificity that elides any direct autobiographical readings.

The dialectics invoked here do not lend themselves to the anthology piece or stand out reading poem. Rather the task of the poem is to expand a sense of what language can do, where the voice of rhythmic syncopated words can lead us without the entrapment 
of specific referents. To ask exactly what each might mean would suggest you need to read either slower or much faster to reel in effect and then move on. These poems have a distinctive kind of music and kept me thinking of the kind of music I should listen to while reading them or hearing them read aloud. Not jazz but certainly electroacoustic, serial, looping back over sounds, quirky in way, distanced and engaging all at the same time:

The blue blouse light and racking, fattening up in the light room high in the ship of the house, meaning to meaning to I was going to

So 'Day' here concludes, or rather signs off by opening us out to new pathways. The meaning the 'I' was going to commit to doesn't quite arrive, and perhaps cannot. But the blue light and the light room may be enough (the poem clearly hopes) for the reader to grasp new things and themselves become part of the dialectic chain of signifying. Of course this could be quite wrong and just inept reading on my part, but my sense is that Samuels' design is an invitation to open out by way of her musically crafted nets of words rather than commit to a Keatsian declaration concerning that saving grace of the artist. The collection is listed as being available in Australia, so the best thing would be to test drive it for yourself. 